\title{
DESIGN AND FABRICATION OF AUTOMATION FOR STAPLING OF WOODEN SUPPORTS TO CORRUGATED BOXES
}

\author{
Aakash Todakar ${ }^{1}$, Siddharth Patil $^{2}$, Ashish Shejwal ${ }^{3}$, Omkar Barve $^{4}$ \\ ${ }^{1}$ B.E, Mechanical, M.I.T., Maharashtra, India \\ ${ }^{2}$ B.E, Mechanical, M.I.T., Maharashtra, India \\ ${ }^{3}$ B.E, Mechanical, M.I.T., Maharashtra, India \\ ${ }^{4}$ B.E, Mechanical, M.I.T., Maharashtra, India
}

\begin{abstract}
The scope of this research is to design an automated system by which stapling of box is done. Automation is key subject for this project. Machine Design and Manufacturing Process were also subjects of interest. Accuracy in manufacturing was necessary for proper functioning of system. First of all various design of system was carried out. After comparing various possibilities in every aspect, final efficient design is selected. Design includes Scissors mechanism, Z- Shaped Base and Robot slide base. Design and selection process includes LM Guides, Actuators, Shock Absorber, Robot, and Indexer. Design stage involved basic machine design techniques and force analysis
\end{abstract}

\section{INTRODUCTION}

With ever increasing demand for goods and services, constant pressure to cut down costs, improve product quality and consistency as well as to improve the worker safety automation has now become a norm in the industries throughout the world. Automation is helping companies to streamline their operations and helps the companies in gaining an edge over their competitors in terms of quality and consistency of the product as well as in terms of customer satisfaction. Automation can be defined as the technology used for the application of integrated mechanical, electronic and computer based systems in the operation and control of production systems. Automation covers a wide range of area ranging from manufacturing, packaging, and transportation. The basic objective of automation is to streamline and synchronize various activities within the industry as well as reduction in the workforce requirement which help in minimizing the errors and maximizing the profits.The Indian motorcycle giant Bajaj Auto Ltd. which is headquartered in Akurdi, Pune with its recent takeover of the Austrian two wheeler manufacturer KTM as well as the collaboration with Kawasaki has seen an increasing demand for two wheelers abroad. Some of these vehicles are exported as Completely Built Units (CBU's) which are packed in corrugated boxes with a wooden support structure. With increasing volumes there developed need for automation to staple wooden supports to the corrugated boxes which was earlier carried out manually.It basically consists of a wooden framework on the top and bottom. This wooden framework along with wooden pillars that are stapled to the corrugated boxes form a sturdy structure which supports and safeguards the vehicle during transportation.

\subsection{Objective}

The pneumatic stapling gun used for the stapling operation comes with a built in safety mechanism that prevents the trigger operation until and unless the stapling gun has been pressed against the object to be stapled. But despite this pneumatic stapling guns are a safety hazard if handled improperly. These stapling guns are responsible for lots of accidents globally. In case of humans there is always a tendency to find ways to reduce the efforts and break the rules of safety. There were a couple of accident encountered in the company and the primary reason observed was the very human tendency to reduce efforts that resulted in the operator bypassing the safety mechanism. As a result of these incidents a primary need was recognized to improve the safety during this operation. Also this activity carried out manually was quite labor intensive requiring three people in order to complete the operation. And as in case of any system man being the biggest variable there was a need recognized to reduce the manpower for this operation.Also cutting costs was also another objective. Another area for improvement was the time required for stapling one box or simply said the cycle time of the stapling operation.

Summary of the objectives:

1) Improving operator safety

2) Reducing manpower requirement

3) Cutting down the costs

4) Reducing the cycle time

\subsection{Constraints}

The following are the constraints for designing the system:

1) Floor space availability $=4000 \mathrm{~mm} X 5000 \mathrm{~mm}$

2) Targeted cycle time $=60$ seconds 


\subsection{Current Scenario}

\section{MANUAL STAPLING OPERATION}

Various activities involved in the manual stapling operation:

1) Loading of the box on fixture

2) Placing of wooden supports in the fixture

3) Manual stapling by one worker using a pneumatic stapling gun

4) Unloading of the box from the fixture

\section{LITERATURE SURVEY}

\subsection{Automation}

Automation can be defined as the technology used for the application of integrated mechanical, electronic and computer based systems in the operation and control of production systems. Automation is not new but has been in industry for quite some time. The automation seems to be a feasible solution for improving the productivity, quality and economy. Manual operations lead to many accidents, poor quality, manpower requirement. Hence automation is best option for efficient process and more productivity. Automation is not feasible in low scale production system but however as the volumes goes on increasing automation becomes more and more economically feasible. Here we are using a fixed automation system. Technical limitation of automation are minimal but there are social and financial limitations, social related are that job opportunity are reduced and that with financial are automation have high initial cost.

\subsection{Product Life Cycle of any Automation Project}

1) Project Concept or 'Need'

2) Initial Specification

3) Front End Engineering Design (FEED)

4) Detailed Engineering Design

5) Build \& Delivery

6) Installation \& Commissioning

7) Support

Brief explanation of the various stages:

Project Concept or 'Need': The birth of any project comes from its need. Need arises either from any inherent problem that is being faced or from the need to improve any process.

Initial Specification: It is basically a list of all the things that would be included in the project. It is mainly aimed at telling the customer something about the product. The specification again may be developed as you work through your project. Changes that may be needed during the project have an effect on the specification, you may want to remove some part of the design and change something else.

Front End Engineering Design (FEED): The FEED is basic engineering which comes after the Conceptual design or Feasibility study. The FEED design focuses the technical requirements as well as rough investment cost for the project.
Detailed Engineering Design: The detailed design portion of the engineering design process is the task where the engineer can completely describe a product through solid modeling and drawings. Some specifications include:

- Operating parameters

- Operating and non-operating environmental stimuli

- Test requirements

- External dimensions

- Maintenance and testability provisions

- Materials requirements

- Reliability requirements

- External surface treatment

- Design life

- Packaging requirements

- $\quad$ External marking

Build \& Delivery: Based on the drawing that are released as an outcome of the detailed design process the various components are manufactured as per the specifications and are further assembled based on the design guidelines. Once the entire assembly is completed functionality tests are carried out and once the product passes all tests the product is ready to be delivered.

Installation \& Commissioning: In practice, the commissioning process comprises the integrated application of a set of engineering techniques and procedures to check, inspect and test every operational component of the project, from individual functions, such as instruments and equipment, up to complex amalgamation such as modules, subsystems and systems.Commissioning activities, in the broader sense, are applicable to all phases of the project, from the basic and detailed design, procurement, construction and assembly, until the final handover of the unit to the owner, including sometimes an assisted operation phase.

Support: This process mainly consists of providing training to the on field workers required for the operation of the equipment as well as provide any technical help required during the operational life of the product.

\subsection{Industrial Robot}

Robot is defined as a reprogrammable multifunctional manipulator designed to move materials, parts, tools, or specialized devices through variable programmed motions for performing a variety of tasks. It is designed for highly repetitive jobs, like in our case the stapling process is a repetitive process which instead is done by robot. The robot technology has established over the period of time. It has taken more than half a century. The first generation robots are referred as dumb robots. These robots strictly work in a fixed sequence. They do not have any sensors which can take corrective action in case of deviations. Then came second generation which was referred as clever robots. They come with a number of sensors which can take corrective action in case of deviations. They are capable of taking logical decisions. The third generations of robots are referred as intelligent robots. They are still in design stage 
they can important decisions. They are designed by using the concept of artificial intelligence. Here we have used universal robots which is modern and flexible industrial robot. They are extremely compact and can be used without any safety guarding. Any faculty with repetitive task is done efficient by these robots. They are light weight and can be moved to some place other easily. Programming is done intuitively. Simply grab the robot arm and show it the desired movement. The robot will then remember the movements. The robot is controlled from a handy, touchsensitive screen with a graphical user interface. On the screen, you can choose from a wide range of useful functions (Teach Pendant.)

\section{Robot Specs:}

6-axis robot arm with a working radius of $850 \mathrm{~mm} / 33.5 \mathrm{in}$

Weight $18.4 \mathrm{~kg} / 40.6 \mathrm{lbs}$

Payload $5 \mathrm{~kg} / 11 \mathrm{lbs}$

Reach: $850 \mathrm{~mm} / 33.5$ in

Joint ranges: $+/-360^{\circ}$ on all joints

Speed: Joint: Max 180\% Approx. 39.4 in/sec.

Repeatability: +/- $0.1 \mathrm{~mm} /$ +/- 0.0039 in (4 mil)

Footprint: $\varnothing 149 \mathrm{~mm} / 5.9$ in

Degrees of freedom: 6 rotating joints

Control box size (WxHxD): $475 \mathrm{~mm}$ x $423 \mathrm{~mm}$ x $268 \mathrm{~mm}$ / $18.7 \times 16.7 \times 10.6$ in

I/O ports: 10 digital in, 10 digital out, 4 analogue in, 2 analogue out

I/O power supply: $24 \mathrm{~V} 1200 \mathrm{~mA}$ in control box and 12 $\mathrm{V} / 24 \mathrm{~V} 600 \mathrm{~mA}$ in tool

Communication: TCP/IP 100 Mbit: IEEE 802.3u, 100BASE-TX

Ethernet socket \& Modbus TCP

Programming: Polyscope graphical user interface on

12 inch touchscreen with mounting

Noise: Comparatively noiseless

IP classification: IP54

Power consumption: Approx. 200 watts using a typical program

Collaboration operation: Tested in accordance with sections

5.10 .1 and 5.10 .5 of EN ISO

10218-1:2006

Materials: Aluminium, ABS plastic

Temperature: The robot can work in a temperature range of $0-50^{\circ} \mathrm{C}$

Power supply: 100-240 VAC, $50-60 \mathrm{~Hz}$

Calculated Operating Life: 35,000 Hours

6 metre / 236 in cable between robot and control box

4,5 metre / 177 in cable between touchscreen and control box.

\section{DESIGN}

\subsection{Initial Layout Plan}

As it has been decided that two robots will be allotted for the project, the entire layout development centered on the two robots. Therefore it was decided that we will be having two stations, one for loading and unloading of the boxes and another for stapling. The only thing that was needed to decide was the way the boxes will travel from one station to another.

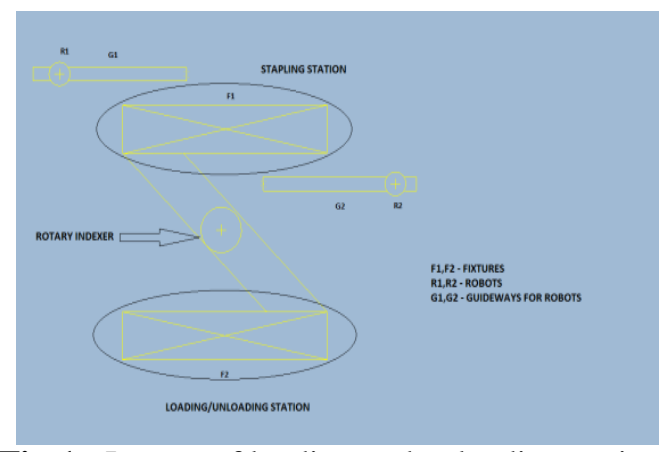

Fig-1: Layout of loading and unloading station.

Based on the above comparisons it is observed that the Layout 2 using the indexer is suitable for our application. Therefore the design is started with Layout 2.

\subsection{Major Subassemblies}

\subsubsection{LM Guides}

The linear motion bearings allows a type of linear motion which uses rolling elements like balls or rollers. By using rolling elements between the rail and block high precision motion is achieved. Compared to traditional slides the coefficient of friction in these is only $1 / 50$. Because of the restraint motion it can take up loads in up/down as well as left/right direction. This greatly helps in enhancing the moving accuracy.

Detailed Selection Process: First we begin with determining the required length based on the geometry of the entire assembly as well as the various constraints.

Therefore, approximate length of the rails $=1800 \mathrm{~mm}$

Next important dimension required is the spacing between the rails. The spacing between the rails depends upon the dimensions of the mounting plate. The dimensions of the mounting plate depend upon the robot mounting considerations as well as the other things that are to be mounted.

Plate dimensions (approx.) $=260 \mathrm{~mm} \times 260 \mathrm{~mm}$

Assuming block width as $60 \mathrm{~mm}$

We get the rail spacing as $200 \mathrm{~mm}$

Next based on the guidelines in the catalogue we select the HG series of the LM guides

Further based on the configuration that would be used we determine the loads on the guide blocks. 


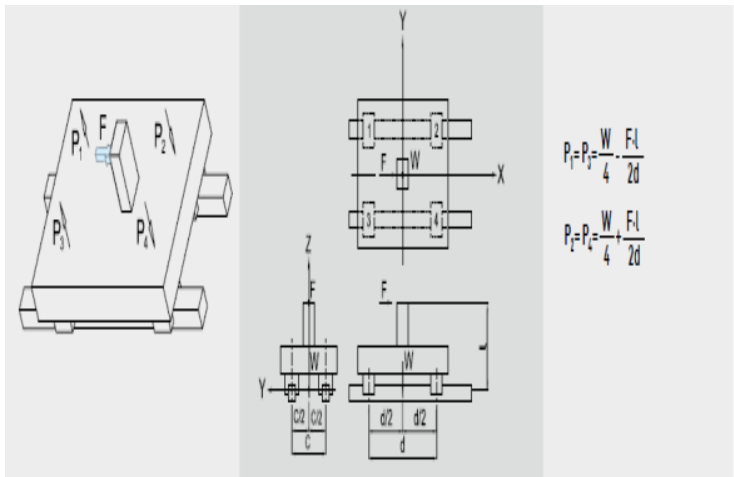

Fig-2: Position where force is acting

Total weight $(\mathbf{W})$

$=$ weight of the robot + weight of the mounting column + weight of the mounting plate

$=(18+18+12) \mathrm{kg}$

$=48 \mathrm{~kg}$

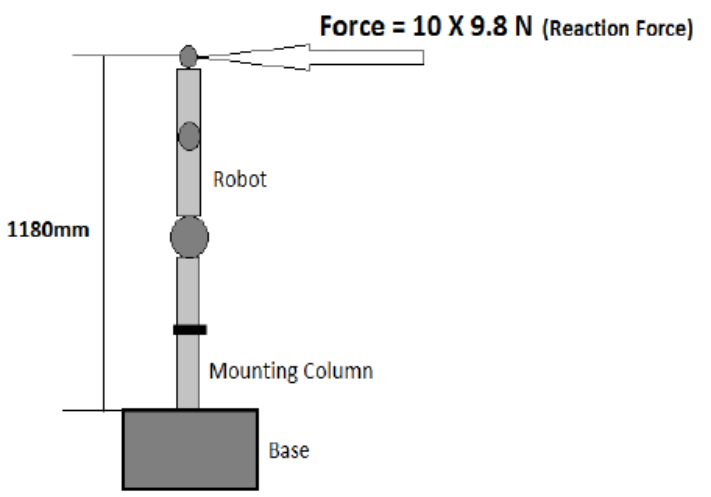

Fig-3: Free body diagram.

Based on the above figure, we have:

$$
\mathbf{F}=10 \times 9.81 \mathrm{~N} ; \mathbf{L}=1180 \mathrm{~mm}
$$

Assuming $\mathrm{d}=100 \mathrm{~mm}$

Based on the load equations shown above,

Maximum load acts on blocks $2 \& 4$

Therefore,

$$
\begin{gathered}
\mathrm{P}_{2}=\mathrm{P}_{4}=\frac{\mathbf{w}}{\mathbf{4}}+\mathbf{F} \times \mathbf{L} /(\mathbf{2} \times \mathbf{d}) \\
\mathrm{P}_{2}=\mathrm{P}_{4}=698.96 \mathrm{~N}
\end{gathered}
$$

Selecting a load factor, $\mathrm{F}_{\mathrm{SL}}=3$

Max. Load $=698.96 \times 3=2096.88 \mathrm{~N}$

Based on the standard lengths available, we select the model HG30. Further we select the CA category indicating heavy load. Therefore the selected model is HG30CA.

Basic Static Load Rating $(\mathbf{C})=52.19 \mathrm{kN}$

Basic Dynamic Load Rating $\left(\mathbf{C}_{\mathbf{0}}\right)=38.74 \mathrm{kN}$
Expected life of the LM guides $=5$ years

Calculating the total distance travelled during the lifetime

Distance travelled per cycle $=3000 \mathrm{~mm}=3 \mathrm{~m}$

Targeted cycle time $=60 \mathrm{sec}$

Total distance travelledper day $=3 \times 10 \times 60=1800 \mathrm{~m}=$ $1.8 \mathrm{~km}$

Therefore, total distance covered in 5 years $=1.8 \times 30 \times 12$ $\times 5$

$=3240 \mathrm{~km}$

Calculating the required dynamic load rating: $\mathbf{L}=\left[\frac{\mathrm{C}}{\mathrm{P}}\right]^{\mathbf{3}} \times \mathbf{5 0}$

Where,

$\mathrm{L}=$ Nominal Life of the LM bearings

$\mathrm{C}=$ Dynamic Load Rating

$\mathrm{P}=$ Max. Load

Substituting the values in the above equation, we get

$\mathrm{C}_{\text {(Required) }}=8.4223 \mathrm{kN}$

$\mathrm{C}_{\text {(actual) }}=38.74 \mathrm{kN}$

Therefore we observe that the selected model of the LM guides is safe.

Model of the Guide and block selected: HGH-30CA.

\subsubsection{Actuator Selection[7][8]}

The major constraint in the selection of the actuator for this application is the space constraints. The desired feature for the probable actuator is compactness. The most widely used actuators on such Special Purpose Machines are conventional pneumatic and hydraulic actuator. The problem with conventional actuators is that they have a large footprint which contradicts to our requirements. Therefore on looking into the various actuators available we could find two actuator that suited our application. First a ball and screw mechanism and second a rodless pneumatic cylinder.However as the compressed air is readily available on the shop floor we zeroed in on the rodless pneumatic cylinder.

Rodless Pneumatic Cylinder: Rodless cylinders are linear devices that use pressurized fluid to move a load within power transfer operations. A rodless cylinder should be used if the footprint of the area is small, when the load needs to be moved some distance from the cylinder itself, and when the load must move within the length of the cylinder.

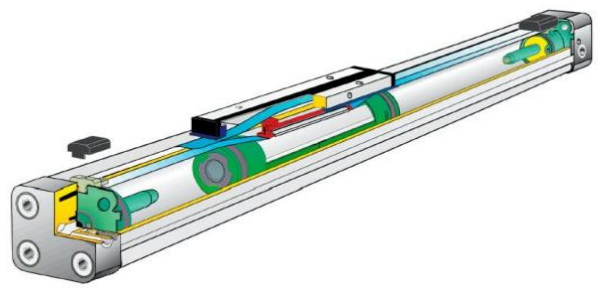

Fig-4: Rodless pneumatic cylinder 
Selection of Rodless Pneumatic Cylinder: The selection process for the rodless pneumatic cylinders is similar to that of the conventional pneumatic cylinders.

We begin with the force that is required to be supplied by the actuator.

This force can be divided into two parts:

1) The frictional resistance on account of the movement of the robot assembly on the LM rails. It is determined by the standard formula:

$$
[1] \mathbf{F}=\boldsymbol{\mu} \times \mathbf{N}
$$

Where,

$\mathrm{F}=$ Frictional force of friction

$$
\begin{aligned}
& \mu=\text { Coefficient } \\
& N=\text { Normal Reaction }
\end{aligned}
$$

Accordingly the various values are as follows:

$\mu=0.05$ (Standard value supplied by the LM rail supplier)

$\mathrm{N}=49 \mathrm{~kg}$ (The total weight supported by the LM rails)

2) The second force will be the external resistance due to the robot drag chain. (The drag chain is a flexible chain that carries the various wires that are required for the functioning of the mobile equipment.)

$$
\mathbf{F}_{\text {ext. }}=10 \times 9.81 \mathrm{~N}(\text { Assumed })
$$

Therefore the total force is the addition of the two forces above

$$
\mathbf{F}_{\text {total }}=122.1345 \mathrm{~N}
$$

We further select a Factor of Safety (FOS) as 4,

To determine the desired bore of the cylinder we use the formula:

\section{Force $=$ Pressure $\times$ Area}

Pressure $=\mathbf{5} \times \mathbf{1 0}^{\mathbf{5}} \mathbf{N} / \mathbf{m}^{\mathbf{2}}$ (Available system pressure)

Area $=\Pi / \mathbf{4} \times \mathbf{D}^{\mathbf{2}}$ (Area for a circle) Where, $\quad \mathrm{D}=$ Bore Diameter

On substituting the values in the above equations, we get:

$\mathbf{D}=35.2711 \mathrm{~mm}$

On referring the catalogue for the Rodless Pneumatic Cylinders Supplied by Festo Pneumatics, the standard sizes of bore available are as follows: 18, 25, 32, and 40 (mm) Therefore we select the bore size as $D=\mathbf{4 0} \mathbf{~ m m}$

Accordingly the model is designated as: DGC-40-1550-GPPV

Further we move on to the selection of shock absorbers.

\subsubsection{Shock Absorber}

The basic purpose of the shock absorbers is to dampen the impact between the sliding robot assembly and the position stops mounted on the supporting structure. The absence of the shock absorber will result into a severe impact loading on the entire robot assembly which is not desirable. [8][9]

The selection of the shock absorber is carried out using the software provided by the manufacturer Festo. Below are the snapshots from the selection software. Therefore based on the output provided by the software the model number of the selected shock absorber is as given: YSRW-16-26

\section{WORK PRESENTATION SYSTEM}

The basic purpose of the work presentation system is to present the work to the robot in a proper a proper position and orientation. The work presentation system is important from the point of view of the efficient functioning of the automation system. The various components that form a part of our work presentation system are as follows:

\subsection{Scissor Fixture}

[9] A scissor lift is a device used for lifting purposes, its objectives is to make the table adjustable to desirable height. A scissor lift provide the most economic dependable and versatile methods of lifting loads, it has few moving parts, which may only require lubrication. This lift table raises the load smoothly to any desired height. Elements of scissor mechanism are top and bottom frame, Scissors arms, cylinder, shafts and bearings. The frame is made up of the scissor arms which are acting as the support to the entire structure. A table bed platform will be at the top of the scissor link arm. Forces and moment, but only few will be taken into consideration because of the symmetry of various joint and parts of the structure, i.e. reaction forces at similar but opposite point will also be similar but might be of different direction when all conditions are met. $\mathrm{M}$ will stand for the moment about any point, while $\omega$ will be the weight inherent in the system (i.e. weight). Also $\mathrm{W}$ will be used to represent applied load i.e. $\mathrm{W}_{\mathrm{x}}, \mathrm{W}_{\mathrm{y}}, \mathrm{W}_{\mathrm{z}}$ \& in the $\mathrm{X}, \mathrm{Y}, \& \mathrm{Z}$ directions.

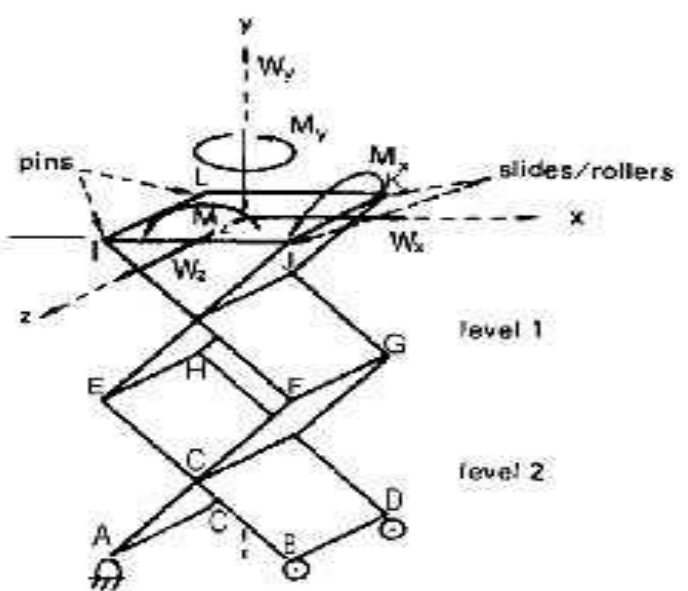

Fig-5: Scissor mechanism. 
Now, since in our case scissor mechanism is used for just support, the load acting on it will be self-weight of scissor. This will be in negative $y$ - direction i.e. downward direction. This is two stage scissor mechanism, with load acting vertically downward.

\section{Free Body Diagram:}

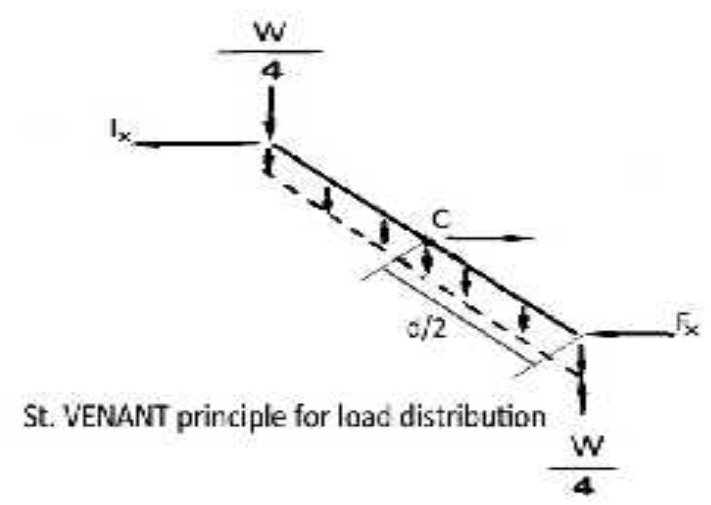

Fig-6: Free body diagram of scissor fixture

Total Load on the system will be applied load plus selfweight.

I.e. Total Load $=$ Applied load + Self weight

$=\mathrm{W}+\mathrm{W}_{\mathrm{g}}=\mathrm{W}_{\mathrm{y}}$

From FBD,

$2 \mathrm{~F}_{\mathrm{y}}-2(\mathrm{~W} / 4)-\left(\mathrm{W}_{\mathrm{g}} / 2\right)=0$;

$\mathrm{F}_{\mathrm{y}}=\left(\mathrm{W}+\mathrm{W}_{\mathrm{g}}\right) / 4$;

$\mathrm{F}_{\mathrm{y}}=\mathrm{W}_{\mathrm{y}} / 4$

Also summation of Moment about point $\mathrm{C}=0$;

$$
2\left(\mathrm{~W}_{\mathrm{y}} / 4\right)(\mathrm{d} / 2) \cos \mathrm{A}=(\mathrm{d} / 2) \sin \mathrm{A}\left(\mathrm{F}_{\mathrm{x}}-\mathrm{I}_{\mathrm{x}}\right)
$$

Since one end of arm is sliding joint, hence let $I_{x}=0$;

Therefore,

$\mathrm{F}_{\mathrm{x}}=\mathrm{W}_{\mathrm{y}} /(2 \tan \mathrm{A})$;

Now,

$\mathrm{C}_{\mathrm{x}}=\mathrm{F}_{\mathrm{x}}+\mathrm{I}_{\mathrm{x}}$

$\mathrm{C}_{\mathrm{x}}=\mathrm{W}_{\mathrm{y}} / \tan \mathrm{A}$;

Calculation: In our case,

Where,

$$
\begin{gathered}
\mathrm{F}_{\mathrm{x}}=\mathrm{W}_{\mathrm{y}} /(2 \tan \mathrm{A})=294.3 \mathrm{~N} \\
\mathrm{~F}_{\mathrm{y}}=\mathrm{W}_{\mathrm{y}} / 2=1378.6 \mathrm{~N}
\end{gathered}
$$

$\mathrm{W}_{\mathrm{y}}=$ self-weight of scissor $=120 \mathrm{~kg}$.

Shaft: According to A.S.M.E code,

Material selected: $20 \mathrm{MnCr} 5$ with $\mathrm{S}_{\mathrm{ut}}=1200 \mathrm{~N} / \mathrm{mm} 2$;

Justification: Has core tensile strength, good wear resistance;

Diameter of shaft $=10.86 \mathrm{~mm}$;

From design table, we select $12 \mathrm{~mm}$ as diameter of shaft.
Bearing: Bearing selected is $6201 \mathrm{z}$. $\mathrm{D}=32 ; \mathrm{d}=12$;

\section{Pneumatic Cylinder:}

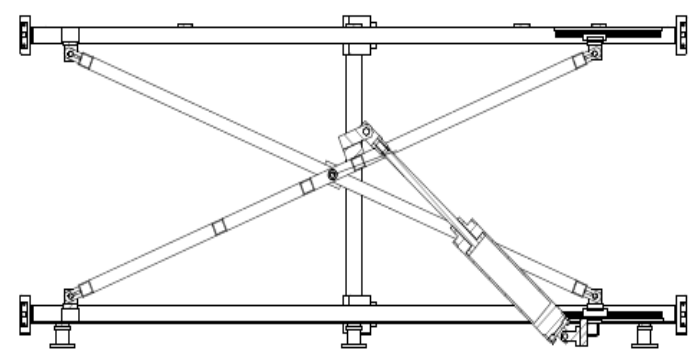

Fig-7: Pneumatic cylinder arrangements

Pneumatic cylinder arrangement: Pneumatic cylinder is used to lift the scissor whenever the box is to be loaded. The sequence is like, first of all scissor is lifted, then box is mounted and then wooden pillars are placed accordingly. The cylinder is lifted up with help of pressurized air, having a pressure of 5 bar.

\section{Calculation:}

Weight to be lifted approx. $=90 \mathrm{~kg}$.

Angle of inclination $(\mathrm{B})=22.778 \mathrm{deg}$.

Force needed to lift $=\mathrm{W} x \mathrm{~g} / \sin \mathrm{B}=2280.443 \mathrm{~N}$

Pressure available $=5$ bar.

Pressure $=$ Force $/$ Area;

Area $=$ Force $/$ Pressure $=2280.443 / 5 \times 10^{5}=4.56 \times 10^{-3}$;

Area $=\Pi / 4 \times \mathrm{d}^{2}$;

$\mathrm{d}=76.2 \mathrm{~mm}$

Based on the standard sizes of the cylinders available as per the Festo catalogue, the pneumatic cylinder with a bore size of $100 \mathrm{~mm}$ is selected.

2) Rotary Indexer: The indexing mechanism is required in order to carry a newly loaded box from the loading/unloading station to the stapling station and carry back the stapled box from the stapling station to the loading/unloading station. The application demands the indexing to be carried out back and forth through an angle of 180 degrees in order to prevent the twisting of the cables and pneumatic hoses. The indexing mechanism can be basically classified as mechanical cam driven systems and servo motors based indexing systems. But as the angle through which indexing is to be done is 180 degrees it makes selection of cam based indexing system viable. Moreover there many other advantages of a mechanical cam based system which are given as follows:

Inertia and weight capacity: They can handle the highestinertia systems.

Repeatability: They are extremely repeatable and give consistent results.

Speed: They move heavier loads at faster speeds than most electronic systems. 
Reliability: High reliability is because of fewer components to fail.

Repetitive motion: This is good for systems requiring accurate repetitive cycles.

Cost effectiveness and simplicity: They can be maintained and operated by less skilled factory personnel, but are impervious to tampering.

Calculations and selection: The indexer is selected according to its inertia capacity. Thus the inertia can be calculated assuming the scissor fixtures as rectangular volume and determining its moment of inertia about an axis perpendicular to the plate and passing through its center and further using the parallel axis theorem to determine the moment of inertia about the indexer axis.

Moment of inertia of a single scissor fixture about indexer axis $=141.186 \mathrm{~kg}-\mathrm{m}^{2}$

Total moment of inertia for two fixtures $=282.373 \mathrm{~kg}-\mathrm{m}^{2}$

Whereas, for the $\mathrm{z}$ shaped structure the moment of inertia is determined by assuming it to be a rectangular plate and further determining its moment of inertia.

Therefore, Moment of inertia of the $\mathrm{z}$ shaped structure about the indexer axis $=264.07 \mathrm{~kg}-\mathrm{m}^{2}$

Total moment of inertia $=282.373+264.07$

$$
=546.433 \mathrm{~kg}-\mathrm{m}^{2}
$$

Thus referring to the catalogue supplied by CDS Indexers, based on the required index angle and the inertia capacity the indexer model CDS TR315is selected which has an inertia capacity of $697 \mathrm{~kg}-\mathrm{m}^{2}$, thus suitable for our application.

\section{Project Outcomes:}

1) Reduction in the worker fatigue: As the worker is relieved of the highly monotonous and tiring job of stapling manually there is significant reduction in the fatigue as the only job that is now required to be carried out by the workers is to place the corrugated box on the scissor fixture followed by placing the wooden supports in place and the unloading of the stapled box after cycle completion.

2) Improved worker safety: As now the stapling activity is carried out by the robots the workers now do not come across the pneumatic stapling gun which is the major source of hazard in the entire operation. Thus operating conditions of the workers are safer.

3) Comparable cycle times: Achieving the desired cycle time for any operation that is automated is one of the biggest challenges faced by the designer. However in this case we have been successful in achieving cycle times comparable to that of the manual activity. The tables shown below:

\section{Manual Activity:}

Table-1: Manual activity chart
\begin{tabular}{|l|l|}
\hline Activity & Time $(\mathbf{s e c})$ \\
\hline Loading box on fixture & 6 \\
\hline Placing wooden supports & 20 \\
\hline Stapling & 60 \\
\hline $\begin{array}{l}\text { Unloading of box from } \\
\text { fixture }\end{array}$ & 6 \\
\hline & $\begin{array}{l}\text { Total time required = } \\
\mathbf{9 2} \text { sec }\end{array}$ \\
\hline
\end{tabular}

\section{Automated Activity:}

Table-2: Automated activity chart

\begin{tabular}{|l|l|}
\hline Activity & Time (sec) \\
\hline $\begin{array}{l}\text { Loading of box on scissor } \\
\text { fixture and raising the fixture }\end{array}$ & 10 \\
\hline Placing wooden supports & 70 \\
\hline Indexing & 8 \\
\hline Stapling by robots & 90 \\
\hline Indexing & 8 \\
\hline $\begin{array}{l}\text { Lowering of scissor fixture } \\
\text { and unloading the box }\end{array}$ & 10 \\
\hline & $\begin{array}{l}\text { Total time } \\
\text { required }=\mathbf{9 8} \mathbf{~ s e c}\end{array}$ \\
\hline
\end{tabular}

In case of the automated activity as the loading/unloading as well as the support placement is being carried out simultaneously with the stapling activity by the robots the effective cycle time is the sum of the time required for stapling or the time required for loading, unloading and pillar placement the greater of the two and the time required for indexing.

\section{CONCLUSION}

Incorporating maximum design principles for our objective to have maximum safety of worker. Here the stapling process needs maximum safety, because some accidents have occurred in past, during stapling due to mishandling of stapling gun by worker. Hence this incident is avoided here because the staple gun and stapling is totally handled by robot. Secondly the stapling is done with high accuracy. But we observe here that time required for process increases by some seconds, but that can be avoided, since our prior goal is safety of worker. In this system worker required will be only one, which in early stage was two. Cost of project is also high, mainly because of robots. Nowadays companies are investing on robots to increase the quality of work, productivity. Hence our research is justified.

\section{REFERENCES}

[1] Design of machine elements by V.B. Bhandari, TataMcGRAW HILL publication.

[2] PSG Design Data Book, PSG College of Technology, 2010 Edition.

[3] Fluid Power and Application, Anthony Esposito, Pearson Publication.

[4] Hiwin Linear guideway catalog_G99TE13-0809. 
[5] Indexing and transfer, Cam Driven System Catalogue.

[6] Shock Absorber Selection Tool, version 5.10.1.8 by FESTO

[7] Rodless Pneumatic Cylinders, FESTO Pneumatics catalogue.

[8] United States Patent - Pneumatic Nail Gun by We Chou Chang, Patent No: US 6533156 B1, March 18,2003 .

[9] Scissor Lift design for use in automotive Industry presented by Macaulay Oletu Stanley UG/07/0898.

\section{BIOGRAPHIES}

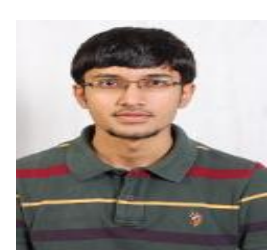

Aakash Todakar, born in Maharashtra, India in 1992. He secured his degree in B.E.- Mechanical from Maharashtra Institute of Technology, pune, in 2014. $\mathrm{He}$ is currently working in Bajaj auto.. He has interest in Future studies and his interested field is Design field

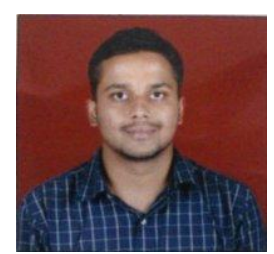

Siddharth Patil, born in Maharashtra, India in 1992. He secured his degree in B.E. Mechanical from Maharashtra Institute of Technology, pune, in 2014. Future studies and interest in Design field andprocess industry.

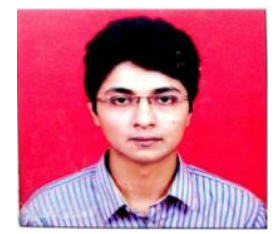

Ashish shejwal, born in Maharashtra, India in 1993. He secured his degree in B.E. Mechanical from Maharashtra Institute of Technology, pune, in 2014. $\mathrm{He}$ has completed his project and worked as Intern at varroc polymers pvt. Ltd. And interned in mahindra and mahindraand volkswagon. Future studies and interest in Design field and metallurgy.

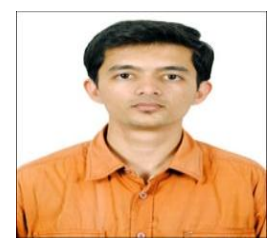

Omkar Barve, born in Maharashtra, India in 1993. He secured his degree in B.E. Mechanical from Maharashtra Institute of Technology, pune, in 2014. Future studies and interest in aerospace field. 